\title{
Knowledge and Opinion of First-Year Pharmacy Students About Herbal/Dietary Supplements
}

\author{
Chioma Nwokochah ${ }^{1}$, Christina Robinson ${ }^{1}$ and Bisrat Hailemeskel ${ }^{2 *}$ \\ ${ }^{1}$ Doctor of Pharmacy Student \\ ${ }^{2}$ Professor \& Vice Chair, Howard University, College of Pharmacy, Washington DC, USA
}

*Corresponding author: Bisrat Hailemeskel, Professor \& Vice Chair Clinical \& Administrative Pharmacy Sciences College of Pharmacy Howard University, USA

\section{ARTICLE INFO \\ Received: 㓞 January 25, 2021 \\ Published: 㓞 February 12, 2021}

Citation: Chioma Nwokochah, Christina Robinson, Bisrat Hailemeskel. Knowledge and Opinion of First-Year Pharmacy Students About Herbal/Dietary Supplements. Biomed J Sci \& Tech Res 33(5)-2021. BJSTR. MS.ID.005467.
ABSTRACT

Background: Herbal and dietary supplements have been the cornerstone of historic pharmaceutical therapy. Cultural attributes and holistic or plant-based modifications have restructured the method in which we supplement our diets. The fact that herbal and dietary supplements are underrepresented in research, downplays the miraculous progression in medicine by way of our natural environment. For this reason, underrepresented groups in research, such as minorities, have undefined knowledge of herbal and dietary supplemental benefits, promoting reliance on prescription medications to self-treat and recommend.

Objective: The objectives of this study are to asses first professional year pharmacy school students, of their knowledge, familiarity, and opinions of dietary and herbal supplements; to explore if participants support more dietary and herbal supplement medical research to incorporate them as first-line therapy; and to learn if students on a budget, would self-medicate more often with herbal supplements for minor illnesses due to proven results.

Methods: Electronic surveys with six questions, were given to 44 first year pharmacy students at a college of pharmacy. The first 2 questions were specific to the quality of medical research toward herbal and dietary supplements and a providers' ability to prescribe said supplements for stress-related issues. The last 4 questions focused on personal approach to finances and preference of prescription medication over herbal supplements.

Results: Most students agreed (88.7\%) that there are not enough medical research supports the quality of herbal and dietary supplements. On the other hand, most students agreed $(80.6 \%)$ that providers should be able to prescribe medicinal marijuana as a firstline treatment for anxiety and stress-related disorders. Over half of students (63.34\%) would consider purchasing herbal supplements for minor ailments. The majority of students $(70.45 \%)$ would still take herbal supplements while having health insurance, even strongly considering replacing prescription medications with herbal supplements, in some cases. Our results revealed overall that students somewhat agreed to having some knowledge of herbal and dietary supplements, enough to contemplate health benefits and cost effectiveness. More justifiable medical research is required to encourage students to consider strongly agreeing in all areas. Dietary and herbal supplements were more favorable to over half of the class in terms of cost and convenience. Despite familiarity, the lack of research of these supplements limited ideas of highly recommending them to patients or further encouraging that they replace prescription medications.

Conclusion: Our study concluded with the suggestion that students' knowledge of herbal and dietary supplements has a great impact on the opinions and willingness to both self-treat and recommend them to their future patients. Despite their believe of lack of good scientific research, study participants were willing to take herbal supplements for themselves to manage minor illness. However, more research is needed to get a more detailed information. 


\section{Introduction}

The purpose of this study is to evaluate the knowledge and opinions of first-year pharmacy students on herbal and dietary supplements. Dietary supplements include vitamins, minerals, amino acids, and herbs or botanicals, as well as other substances that can be used to supplement the diet. Herbal supplements are a type of dietary supplement regulated by the Food and Drug Administration (FDA) [1]. Even though herbal supplements are readily available both in stores and on the internet, pharmacists do not routinely recommend herbal supplements as a first-line defense for temporary relief of symptoms instead of OTC prescription medications. A study done in 2017 to compare dietary supplement use between 179 student pharmacists and the general population, and assess knowledge, attitudes toward use, and dietary supplement effectiveness; and to explore how student pharmacists view their education on dietary supplements found that $52 \%$ had used at least one dietary supplement in their lifetime versus $25 \%$ in the general population [2]. Students perceived supplement label information as unhelpful, research into supplements inadequate, and supplements non-essential to health. Students thought supplement knowledge was important, but their education was inadequate. In another study published on Complementary Therapies in Medicine, positive attitudes, and willingness to recommend dietary supplements to patients were evaluated among 506 students from Pharmacy, Dental, and Medical schools from a single university [2].

Pharmacy students scored highest in both areas [2]. As with over the counter (OTC) and prescription medications, pharmacy students should have a firm working knowledge of common dietary and herbal supplements. The study revealed that the knowledge disadvantage impacted the willingness to recommend rather than personal usage of dietary supplements [2]. The study did not further evaluate the pharmacy students' opinion on replacing prescription medication with dietary supplements for minor illnesses even if there were better research. A similar study done with 355 pharmacy students, 168 were reposted to using at least one dietary supplement, mainly to treat health problems [3]. A review of studies among U.S. and Canadian pharmacists' attitudes, knowledge, and professional practice behaviors toward dietary supplements: a systematic reported they were not possible to draw a conclusion with respect to pharmacists' general attitudes toward dietary supplements. However, they reported that approximately equal numbers of pharmacists report positive as well as negative attitudes about the safety and efficacy of dietary supplements. They stated that there was a strong agreement among pharmacists for the need to have additional training on dietary supplements, increased regulation of DS, and quality information on DS. In addition, survey data in this study also indicated that pharmacists do not perceive their knowledge of dietary supplements to be adequate and that pharmacists do not routinely document, monitor, or inquire about patients' use of dietary supplements.
Despite this, a large proportion of pharmacists reported receiving questions about dietary supplements from patients and other health care practitioners. People use dietary supplements for a wide range of reasons including to compensate for diets, medical conditions, or eating habits that limit the intake of essential vitamins and nutrients; and postmenopausal women often times using dietary/herbal supplements to regulate estrogen levels [4]. Furthermore, according to a study done by Lakhan, herbal supplementation is an effective treatment option for treating anxiety without the risk of serious adverse effect [3]. Seeing that there is an array of uses for herbal supplements, the goal of this study is to find out whether pharmacy students would self-medicate more often with herbal supplements for minor illnesses if there were better research to prove results, and also to identify their opinion on the overall use of dietary supplements. The results of this study will help improve the education and training of pharmacy students on the knowledge of herbal/dietary supplements.

\section{Methods}

A survey was distributed to 44 first-year professional pharmacy students. The survey consisted of six questions plus 8 demographics related questions. The first two questions focused on the quality of medical research and a provider's ability to prescribe herbal supplements for stress- related issues. The last four questions revealed the cognizance of a "students' finances and overall deliberation prior to selecting an herbal or dietary supplement over a prescription [4]. The survey questions were constructed by the research team using Qualtrics and distributed via email to the class of 2024. This study was conducted as a part of a drug informatics course, which is a mandatory course for firstyear pharmacy students. The survey was sent to 44 students and 44 students responded (100 percent response rate). The data was rated on a 4-point Likert Scale (strongly agree to strongly disagree). A descriptive analysis was completed using SPSS software.

\section{Results}

A total of 44 first-year pharmacy students completed demographic-based survey questions for this study. The demographics of this population are represented by $27.73 \%$ male students and $77.27 \%$ female students. In addition, $59.09 \%$ of the students are between the ages of 18 - 24 years old and $40.91 \%$ are between the ages of 25 - 34 years old. As Howard University is located in Washington, D.C., only $9.09 \%$ of first-year pharmacy students have resided in Washington, D.C. prior to admission, while $47.72 \%$ of students have resided in the surrounding areas of Maryland (27.27\%) and Virginia (20.45\%). And 43.18\% of pharmacy students have resided in other states prior to admission. Of the demographic survey questions, pharmacy students were asked about information regarding their highest level of education prior to pharmacy school enrollment. Most first-year pharmacy 
students at Howard University completed a 4-year degree program prior to pharmacy school (59.09\%). Other students completed some college $(27.27 \%)$, few students had a 2 -year college degree (4.55\%), and $9.09 \%$ of students completed a professional degree before entering pharmacy school. Prior to admission into the Howard University College of Pharmacy program, most students had been employed (95.45\%) as opposed to unemployed (4.55\%).

The annual income of the pharmacy students who had prior employment range from less than $\$ 10,000$ (39.53\%) to greater than $\$ 49,999$ (11.63\%) with the rest in between [5]. Of the pharmacy students who had previous work experience, most of the students had pharmacy-related work experience $(62.79 \%)$. The other previously employed pharmacy students either had non-pharmacy but healthcare-related work experience (20.93\%) or non-pharmacy or non-healthcare-related work experience (16.28\%). The years of work experience among previously employed students ranged from less than 1 year $(16.28 \%)$ to greater than 5 years of employment (25.58\%) (Table 1$)$. In addition to demographic-based survey questions, the survey participants also answered a total of six knowledge-based questions about herbal and dietary supplements. More than half of the pharmacy students surveyed somewhat agree or strongly agree (59.09\%) that enough medical research has been done to prove the efficacy and quality of herbal supplements. In addition, the majority of students strongly agree or somewhat agree (79.55\%) that providers should be able to prescribe medicinal marijuana as a first-line treatment for the management of anxiety or stress-related disorders. Most pharmacy students (63.64\%) would consider purchasing any herbal supplement for minor ailments. Many students (70.45\%) would still take herbal supplements if needed even if they have health insurance [6].

Table 1: Demographic data.

\begin{tabular}{|c|c|}
\hline Gender & \% \\
\hline Male & $27.73 \%$ \\
\hline Female & $77.27 \%$ \\
\hline \multicolumn{2}{|c|}{ Age } \\
\hline $18-24$ & $59.09 \%$ \\
\hline
\end{tabular}

\begin{tabular}{|c|c|}
\hline $25-34$ & $40.91 \%$ \\
\hline \multicolumn{2}{|c|}{ State of Residence Prior to Admission } \\
\hline Washington, DC & $9.09 \%$ \\
\hline Maryland & $27.27 \%$ \\
\hline Virginia & $20.45 \%$ \\
\hline Other states & $43.18 \%$ \\
\hline \multicolumn{2}{|c|}{ Employment Prior to HU Pharmacy Program? } \\
\hline Yes & $95.45 \%$ \\
\hline No & $4.55 \%$ \\
\hline Annual Income from Job & $\%$ \\
\hline Less than $\$ 10,000$ & $39.53 \%$ \\
\hline$\$ 10,000-\$ 19,999$ & $16.28 \%$ \\
\hline$\$ 20,000$ - $\$ 29,999$ & $6.98 \%$ \\
\hline$\$ 30,000$ - \$39,999 & $18.60 \%$ \\
\hline$\$ 40,000-\$ 49,999$ & $6.98 \%$ \\
\hline$>\$ 49,999$ & $11.63 \%$ \\
\hline \multicolumn{2}{|c|}{ Type of Work Experience } \\
\hline Pharmacy Related & $62.79 \%$ \\
\hline Non-Pharmacy but Healthcare Related & $20.93 \%$ \\
\hline Non-Pharmacy or Non-Healthcare Related & $16.28 \%$ \\
\hline \multicolumn{2}{|c|}{ Years of Work Experience } \\
\hline$<1$ & $16.28 \%$ \\
\hline $1-3$ & $32.56 \%$ \\
\hline $4-5$ & $25.58 \%$ \\
\hline$>5$ & $25.58 \%$ \\
\hline \multicolumn{2}{|c|}{ Highest Education Prior to Pharmacy School } \\
\hline Some college & $27.27 \%$ \\
\hline 2-year Degree & $4.55 \%$ \\
\hline 4-year Degree & $59.09 \%$ \\
\hline Professional Degree & $9.09 \%$ \\
\hline Doctorate & $0 \%$ \\
\hline
\end{tabular}

The majority of students (70.46\%) believe herbal supplements in some cases can replace prescription medications. Lastly, pharmacy students either strongly agree (31.82\%) or somewhat agree $(40.91 \%)$ that they know where to find information about the use of herbal supplements for a particular condition (Table 2).

Table 2: Responses to questions related to herbal and dietary supplements.

\begin{tabular}{|c|c|c|c|c|}
\hline & Strongly Agree & $\begin{array}{l}\text { Somewhat } \\
\text { Agree }\end{array}$ & $\begin{array}{l}\text { Somewhat } \\
\text { Disagree }\end{array}$ & $\begin{array}{l}\text { Strongly } \\
\text { Disagree }\end{array}$ \\
\hline $\begin{array}{l}\text { I think enough medical research has been done to prove the efficacy and quality of } \\
\text { herbal supplements. }\end{array}$ & $5(11.4 \%)$ & $21(47.7 \%)$ & $9(20.5 \%)$ & $9(20.5 \%)$ \\
\hline $\begin{array}{l}\text { Providers should be able to prescribe medicinal marijuana as a first-line treatment } \\
\text { for the management of anxiety or stress-related disorders. }\end{array}$ & $14(31.8 \%)$ & $21(47.7 \%)$ & $4(9.1 \%)$ & $5(11.4 \%)$ \\
\hline I would consider purchasing any herbal supplement for minor ailments & $11(25 \%)$ & $17(38.6 \%)$ & $9(20.5 \%)$ & $7(15.9 \%)$ \\
\hline I would still take herbal supplements if needed even if I have a health insurance & $11(25 \%)$ & $20(45.6 \%)$ & $7(15.9 \%)$ & $6(13.6 \%)$ \\
\hline I believe herbal supplements in some cases can replace prescription medications & $10(22.7 \%)$ & $21(47.7 \%)$ & 7 (15.9\%) & $6(13.6 \%)$ \\
\hline $\begin{array}{l}\text { I know where I can find information about the use of herbal supplements for a } \\
\text { particular condition. }\end{array}$ & $14(31.8 \%)$ & $18(40.9 \%)$ & $6(13.6 \%)$ & $6(13.6 \%)$ \\
\hline
\end{tabular}




\section{Discussion}

The data collected from the study survey questions has revealed that first-year pharmacy students have a general knowledge of herbal and dietary supplements. In fact, per survey responses, $59.09 \%$ of pharmacy students are confident in the efficacy and quality of herbal supplements proven by medical research. Although this is not an overwhelming percentage of confidence in the efficacy and quality of herbal supplements, the data is positive. Several factors could contribute to their level of confidence such as a students' level of education. Given the demographics of the first-year pharmacy students surveyed, 59.09\% of the students have a 4 -year degree; in addition to $9.09 \%$ of students who have a professional degree. The higher the level of education, the potential for an increased level of confidence in medical research conducted on herbal supplements is greater. There is a general consensus among pharmacy students $(79.55 \%)$ that providers should be able to prescribe medicinal marijuana as a first-line treatment for the management of anxiety or stress-related disorders. Firstyear pharmacy students at Howard University are educated on the chemistry and pharmacology of antidepressants and antianxiety medications. Having proficient knowledge on these medications exposes students to the awareness of the undesirable side effects and drug interactions that could potentiate from administering antidepressants and anti-anxiety drugs, such as the altering of behavior and mood. Due to these negative side effects, administering medicinal marijuana may seem more promising as a first-line treatment for these disorders.

Furthermore, most pharmacy students (63.64\%) would consider purchasing any herbal supplement for minor ailments, as well as $70.46 \%$ of students who believe herbal supplements in some cases can replace prescription medications. Additionally, $70.45 \%$ of pharmacy students would still take herbal supplements if needed even if they have health insurance. Again, several factors could contribute to these opinions of most pharmacy students such as knowledge of the risks associated with taking certain medications or even the type of work experience these students had prior to starting pharmacy school. At Howard University College of Pharmacy, $62.79 \%$ of first-year pharmacy students had previous pharmacy-related work experience. In addition to $20.93 \%$ of students who did not have pharmacy experience but had other healthcare-related experiences. Exposure to working with prescription medications in a pharmacy setting or other healthcare-related settings could influence a student's opinion on the use of herbal and dietary supplements in the place of prescribed medications. A majority of the surveyed pharmacy students (72.73\%) also know where to find information about the use of herbal supplements for a particular condition. First-year pharmacy students at Howard University take a drug informatics course that educates students on drug information services which includes education on drug and herbal products. This shows that many first-year pharmacy students have working knowledge of available resources detailing the use of herbal supplements for a particular condition.

Although there were only 6 survey questions related to herbal and dietary supplements, the objectives of this study were still met. The addition of more survey questions may increase the range of herbal and dietary knowledge and opinions amongst pharmacy students. From the data presented, it is shown that first-year pharmacy students at Howard University have sufficient knowledge of herbal and dietary supplements.

\section{Conclusion}

Our results conclude that knowledge of herbal and dietary supplements influences the opinion of first-year pharmacy students. When asked if supplements could replace prescription medications, most students (47.73\%) somewhat agreed. Because students extensively study the risks and benefits of prescription medications, it is assumed that more justifiable research is needed to strongly agree. Most students (72.73\%) know where to find information on supplements for health conditions, yet if affordability or timing of an appointment is not conducive, they may select a temporary OTC. Economically, health insurance is expensive, and if more research were dedicated to dietary supplements, the majority of students (70.45\%) who agreed would have affordable options for treatment. As it relates to stress and anxiety management that pharmacy students oftentimes endure, medicinal marijuana should be considered as first-line treatment. Antidepressants and antianxiety medications alter mood and behavior which does not gain the approval of most students who need that time to focus on their coursework. Overall, herbal, and dietary supplements are widely used amongst first-year pharmacy students at Howard University. Our study suggests that their knowledge does impact their opinions and willingness to both personal use and recommendations of herbal and dietary supplements to their future patients.

\section{References}

1. (2017) Herbal Supplements: What to Know before You Buy." Mayo Clinic, Mayo Foundation for Medical Education and Research.

2. Axon DR, Vanova J, Edel C, Slack M (2017) Dietary Supplement Use, Knowledge, and Perceptions Among Student Pharmacists. Am J Pharm Educ 81(5): 92.

3. Nakhal SA, Domiati SA, Mohamed I (2020) Assessment of pharmacy students' knowledge, attitude, and practice toward herbal dietary supplements. Journal of American College Health p. 1-5.

4. Bukic J, Rusic D, Bozic J, Zekan L, Leskur D, et al. (2018) Differences among health care students' attitudes, knowledge and use of dietary supplements: A cross-sectional study. Complementary therapies in medicine 41: 35-40.

5. (2020) FDA 101: Dietary Supplements. U.S. Food and Drug Administration, FDA.

6. Lakhan SE, Vieira KF (2010) Nutritional and herbal supplements for anxiety and anxiety-related disorders: Systematic review. Nutr J 9: 42. 


\section{ISSN: 2574-1241}

DOI: 10.26717/BJSTR.2021.33.005467

Bisrat Hailemeskel. Biomed J Sci \& Tech Res

(CC) (i) This work is licensed under Creative (c) BY Commons Attribution 4.0 License

Submission Link: https://biomedres.us/submit-manuscript.php

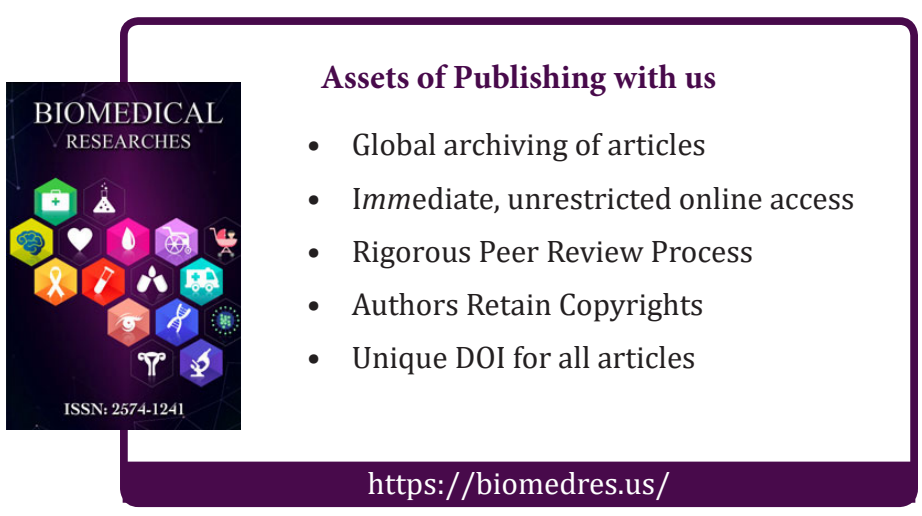

